\title{
Selection of RNA aptamers imported into yeast and human mitochondria
}

\author{
OLGA KOLESNIKOVA, ${ }^{1,2}$ HELENA KAZAKOVA, ${ }^{1,2}$ CAROLINE COMTE, ${ }^{1}$ SERGEY STEINBERG, ${ }^{3}$ \\ PIOTR KAMENSKI, ${ }^{1,2}$ ROBERT P. MARTIN, ${ }^{1}$ IVAN TARASSOV ${ }^{1}$ and NINA ENTELIS ${ }^{1}$ \\ ${ }^{1}$ UMR 7156, Université de Strasbourg/Centre National de la Recherche Scientifique (UdS/CNRS), 67084 Strasbourg, France \\ ${ }^{2}$ Department of Molecular Biology, Moscow State University, Moscow 119899, Russia \\ ${ }^{3}$ Department of Biochemistry, Montreal University, Montreal H3C3J7, Canada
}

\begin{abstract}
In the yeast Saccharomyces cerevisiae, nuclear DNA-encoded tRNA $\mathrm{CUU}_{\mathrm{Cu}}^{\mathrm{Lys}}$ is partially imported into mitochondria. We previously found that the synthetic transcripts of yeast tRNA ${ }^{\text {Lys }}$ and a number of their mutant versions could be specifically internalized by isolated yeast and human mitochondria. The mitochondrial targeting of $t R N A^{\text {Lys }}$ in yeast was shown to depend on the cytosolic precursor of mitochondrial lysyl-tRNA synthetase and the glycolytic enzyme enolase. Here we applied the approach of in vitro selection (SELEX) to broaden the spectrum of importable tRNA-derived molecules. We found that RNAs selected for their import into isolated yeast mitochondria have lost the potential to acquire a classical tRNA-shape. Analysis of conformational rearrangements in the importable RNAs by in-gel fluorescence resonance energy transfer (FRET) approach permitted us to suggest that protein factor binding and subsequent import require formation of an alternative structure, different from a classic L-form tRNA model. We show that in the complex with targeting protein factor, enolase 2, tRK1 adopts a particular conformation characterized by bringing together the $3^{\prime}$-end and the TWC loop. This is a first evidence for implication of RNA secondary structure rearrangement in the mechanism of mitochondrial import selectivity. Based on these data, a set of small RNA molecules with significantly improved efficiency of import into yeast and human mitochondria was constructed, opening the possibility of creating a new mitochondrial vector system able to target therapeutic oligoribonucleotides into deficient human mitochondria.
\end{abstract}

Keywords: mitochondrial tRNA import; RNA aptamers; small synthetic RNAs; SELEX; in-gel FRET

\section{INTRODUCTION}

Mitochondrial import of nuclear DNA-encoded tRNAs is a widespread phenomenon. It was characterized in a variety of species, and apparently unrelated molecular mechanisms have been discovered for protozoa, higher plants, and yeast (for review, see Tarassov et al. 2007; Salinas et al. 2008; Duchene et al. 2009). In the yeast Saccharomyces cerevisiae, cytosolic tRNA ${ }_{\text {CUU }}^{\text {Lys }}$ (hereafter referred to as tRK1) is partially targeted into mitochondria (Martin et al. 1977). This process was shown to be essential for mitochondrial protein synthesis at elevated temperatures, when the mitochondrially encoded tRNA $\mathrm{U}_{\mathrm{U} * \mathrm{UU}}^{\mathrm{Lys}}$ becomes undermodified at the wobble position of the anticodon and thus can no longer recognize the lysine codon AAG (Kamenski et al.

Reprint requests to: Nina Entelis, UMR 7156, Université de Strasbourg/ Centre National de la Recherche Scientifique (UdS/CNRS), 21 rue René Descartes, 67084 Strasbourg, France; e-mail: N.Entelis@ibmc.u-strasbg.fr; fax: +33 3-88-41-70-70.

Article published online ahead of print. Article and publication date are at http://www.rnajournal.org/cgi/doi/10.1261/rna.1914110.
2007). Import of two other cytosolic tRNAs, tRNA $\mathrm{GUG}_{\mathrm{CU}}^{\mathrm{ln}}$ and $\mathrm{tRNA}_{U \mathrm{GG}}^{\mathrm{Gln}}$, proposed to be essential for decoding of CAG glutamine codon (Rinehart et al. 2005), however, was not detected in yeast mitochondria in a more recent study (Frechin et al. 2009). It has long been believed that human mitochondria do not import tRNAs; however, import of nucleus-encoded tRNA ${ }^{\text {Gln }}$ in human and rat mitochondria was recently reported (Rubio et al. 2008). Previously we demonstrated that human mitochondria are able to import yeast tRK1 (Kolesnikova et al. 2000), and this artificially established import was successfully used for a partial rescue of the dysfunctions associated with MERRF mutation in the mtDNA (Kolesnikova et al. 2004).

The molecular mechanism of tRK1 mitochondrial targeting in yeast involves an interaction with protein factors that enables the RNA to escape the cytosolic protein synthesis cycle. We have previously shown that a part of aminoacylated cytosolic tRNA $\mathrm{CUU}_{\mathrm{CU}}$ can be specifically recognized by one of the two isoforms of the glycolytic enzyme enolase, Eno2p (Entelis et al. 2006). This tRNA-enolase complex then transits to the mitochondrial surface, where 
enolase can be incorporated into a glycolytic multiprotein complex (Brandina et al. 2006), whereas tRK1 is taken up by the precursor of mitochondrial lysyl-tRNA synthetase, preMSK1p, which serves as the carrier for tRK1 translocation into the mitochondrial matrix (Tarassov et al. 1995). In this interplay between two proteins, enolase was hypothesized to function as an RNA chaperone, increasing the affinity of tRK1 for preMSK1p (Entelis et al. 2006); however, the details of this mechanism remained unclear.

Interaction of imported tRNA with protein factors is a key moment for the selectivity of the mitochondrial import. The molecular mechanism of discrimination between imported tRK1 and all the other cytosolic tRNAs was still unknown. Using mutagenesis followed by in vitro and in vivo import assays, we have previously found that not only is tRK1 imported into yeast mitochondria, but also several of its mutant versions, mutants of the second cytosolic lysine isoacceptor tRNA, normally nonimported tRNA $\mathrm{L}_{\mathrm{U} * \mathrm{UU}}^{\mathrm{Lys}}$ (tRK2), and even a synthetic transcript of the mitochondrially localized tRNA $_{\mathrm{U} * \mathrm{UU}}^{\mathrm{Lys}}$ (tRK3) (Entelis et al. 1996, 1998; Kolesnikova et al. 2002). Systematic analysis of the sequences of imported versions permitted us to discern the determinants (the first base pair G1-C72 and U73 in the acceptor stem and C34 in the anticodon) and an anti-determinant (modified U34) that controls mitochondrial import specificity (Fig. 1A). However, these determinants can be considered as context-dependent. For example, insertion of a base $\mathrm{C}$ in the wobble position of the normally nonimported tRK2 leads to its import, which means that this position may be a part of the import signature. On the other hand, substitution of C34 in tRK1 by U34 (as in tRK2) does not affect the import, only replacement of all the anticodon arm of tRK1 by that of tRK2 results in such an inhibition (Entelis et al. 1998). Furthermore, it was shown that replacement of bases in the middle of the AA-stem blocks preMSK1p binding and the import of tRK1 but does not lead to import of tRK2 (Kazakova et al. 1999). These results raised the question, to what extent may the import machinery be flexible, and is it possible to discern the import signature, in terms of sequence motif(s) or structural elements? Here we address this question by using the approach of in vitro selection (systematic evolution of ligands by exponential [SELEX] enrichment) (Tuerk and Gold 1990). Based on these data, a set of small RNA molecules with significantly improved efficiency of import into yeast and human mitochondria was constructed, opening the possibility of creating a new mitochondrial vector system able to target therapeutic oligoribonucleotides into deficient human mitochondria.

Analysis of all importable RNAs obtained in selection experiments allows us to suggest that at least one of the tRNA mitochondrial import determinants consists in the possibility of forming an alternative structure, different from a classic L-form tRNA model. To prove the real existence of such a conformational rearrangement, we used the in-gel fluorescence resonance energy transfer (FRET) approach (Radman-Livaja et al. 2005). We show that in the complex with the targeting protein factor enolase, tRK1 adopts a particular conformation characterized by bringing together nucleotides C56 and A75. This is a first evidence for implication of RNA secondary structure rearrangement in the mechanism of mitochondrial import selectivity.

\section{RESULTS}

\section{Strategy for RNA selection from libraries of randomized RNAs}

The initial RNA library was generated by $\mathrm{T} 7$ transcription on a 73-mer oligonucleotide corresponding to yeast tRNA ${ }_{\mathrm{CUU}}^{\text {Lys }}$ (tRK1) that contained 14 random nucleotides in positions that differ between imported tRK1 and nonimported tRNA $\mathrm{A}_{\mathrm{U} * \mathrm{UU}}^{\text {Lys }}$ (tRK2); the three anticodon nucleotides were also randomized (Fig. 1A; Table 1). The resulting library therefore contained $2.7 \times 10^{8}$ possible sequences. This library was subjected to selection assays using two strategies (Fig. 1B,C).

The first one was to select RNAs by several rounds of import into isolated yeast mitochondria followed by RTPCR amplification of RNA purified from RNase-treated mitochondria (selection for import [SI]) (Fig. 1B). Thus, we selected RNAs capable of entering into the mitochondria and remaining stable there for at least $1 \mathrm{~h}$.

The second strategy was to select RNAs for preMSK1pbinding ability prior to the mitochondrial import in each round of amplification (selection for import and preMSK1p affinity [SIM]) (Fig. 1C). The specificity of RNA binding to immobilized preMSKp was verified by comparison of aminoacylated tRK1 binding versus tRK2 (Fig. 1D). Our previous results indicated that aminoacylation of tRK1 is a prerequisite to allow interaction with preMSK1p; however, some mutant forms of the tRK1 acquired preMSK1pbinding capacities in their deacylated form (Entelis et al. 1998). Our randomized RNA library (S0) was shown to have the same low pre-MSK-binding capacity either with or without pre-aminoacylation by yeast cytoplasmic LysRS (KRS1p). Therefore, we made the further selection experiments without aminoacylation of RNA libraries prior to preMSK1p binding, thus selecting the RNAs able to bind preMSK1p in their deacylated form.

\section{Characterization of different pools of selected RNAs}

After each cycle of selection, an aliquot of every RNA pool was analyzed for preMSK1p binding and import capacity (Fig. 1D,E). The initial RNA library (pool S0) was characterized by a very low level of import. In the RNA pools of the SI series, we observed an increase of import capacity. Already at cycle 5, the import efficiency was similar to that of tRK1, while the average import efficiency of the RNA pool after the eighth cycle was 2.5 times higher than that of tRK1. Thus, the enhancement of import from S0 to SI8 RNA pools was about 30-fold. PreMSK1p-binding capacities of all SI libraries were rather low, as expected in the absence of selective pressure. 

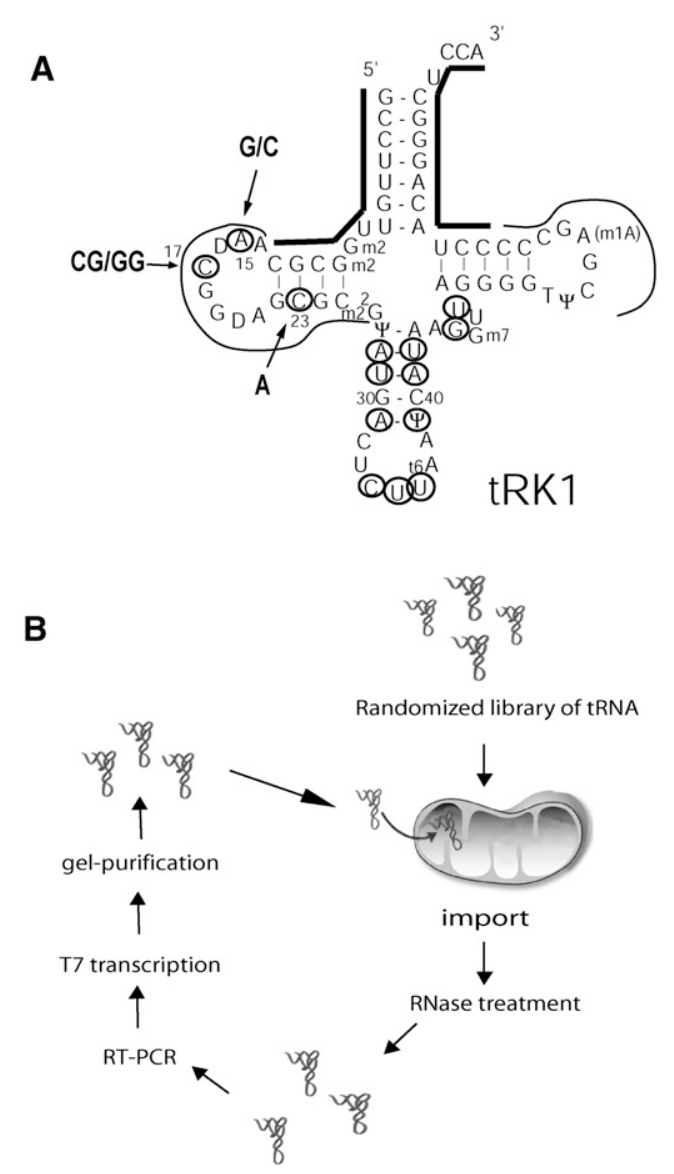

RNAs isolated from mitochondria

D Binding of RNA libraries to pre-MSK

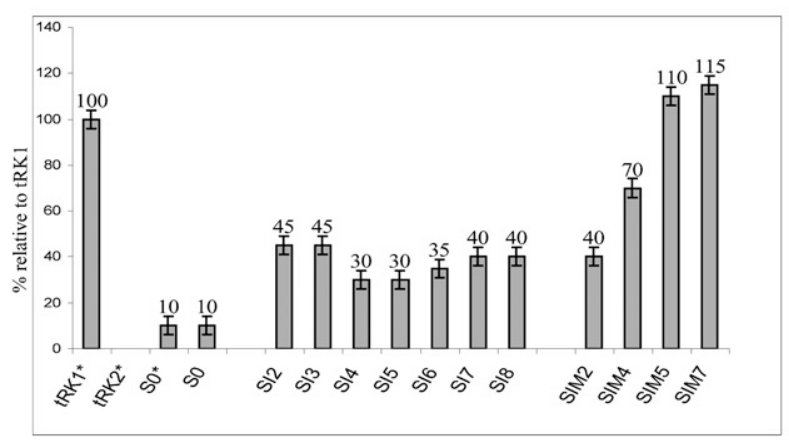

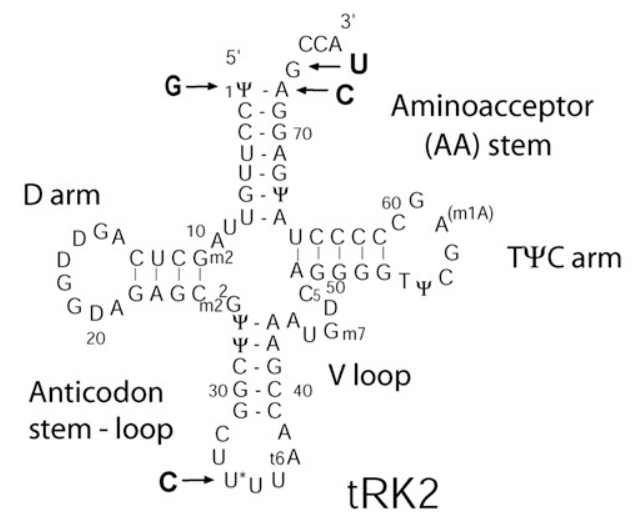

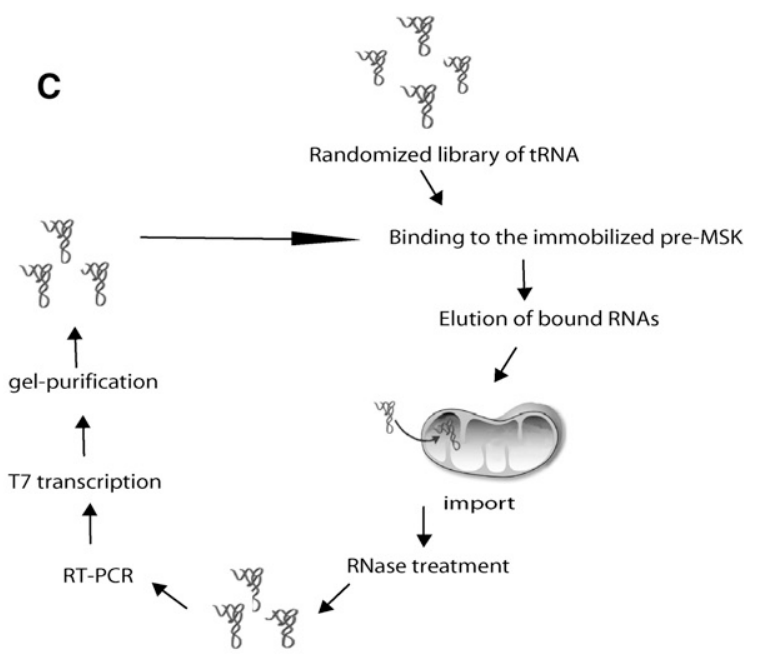

RNAs isolated from mitochondria

E Import of RNA libraries after different rounds of selection

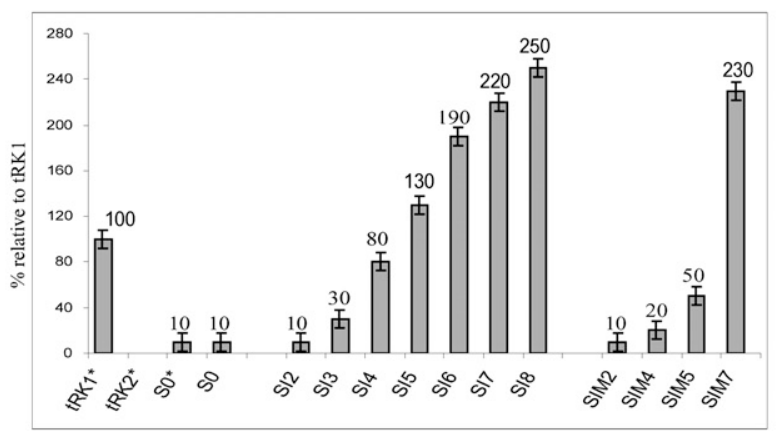

FIGURE 1. (A) Cloverleaf structures of yeast lysine tRNAs, partially imported into mitochondria tRK1 and nonimported tRK2. The import determinants identified previously are indicated by arrows on the tRK2 structure. The tRK1 regions determined by oligonucleotides used for RTPCR are shown by bold lines, residues that have been randomized for SELEX experiment are circled, and regions conserved in all the selected RNA aptamers are indicated by thin lines. Selected substitutions in the D-arm of tRK1 are shown by arrows. $(B, C)$ Strategy for in organello RNA selection. Scheme of randomized RNA library selection $(B)$ for import into isolated yeast mitochondria and $(C)$ for both affinity to preMSK1p and mitochondrial import. $(D, E)$ Characterization of RNA pools resulting from different rounds of selection: $(D)$ preMSK1p-binding capacity; $(E)$ efficiency of mitochondrial import, in percent relative to tRK1. (S0) Initial RNA library; (SI2-SI8) RNA pools after two to eight rounds of selection for the import into mitochondria; (SIM2-SIM7) RNA pools after two to seven rounds of selection for preMSK1p binding and mitochondrial import. RNAs marked by ${ }^{\star}$ were aminoacylated prior to the test. All experiments were performed at least twice in an independent way; standard deviations values are indicated. 


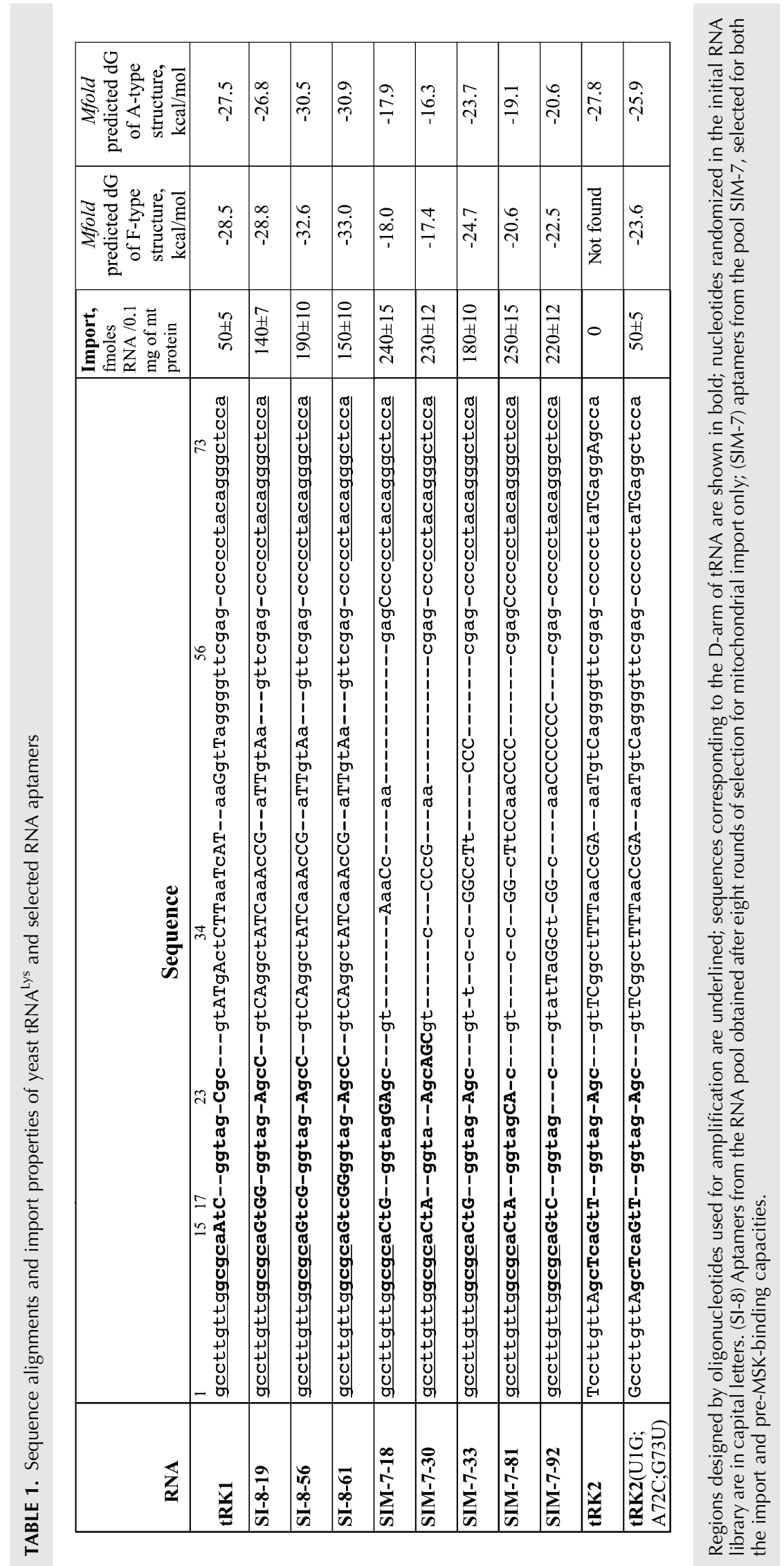


In the SIM series, the efficiency of import increased only slightly from the second to the fifth cycle. We therefore changed the conditions of RNA selection to make them more stringent by decreasing the concentration of mitochondria in the import mixture and, indeed, obtained a 2.3-fold increase of import efficiency in comparison with tRK1 at the seventh cycle. As opposed to the SI series, the SIM one was characterized by a gradual increase of preMSK1pbinding ability to reach the affinity comparable to that of tRK1 already at the fifth round of selection (Fig. 1D).

\section{Analysis of individual aptamers}

Resulting RT-PCR amplified pools after the eighth round of selection in the SI series (named SI-8) and after the seventh round in the SIM series (SIM-7) have been cloned, and 25-35 plasmids from each library were sequenced. All the sequences of selected RNAs were thoroughly analyzed for the presence of characteristic motifs and highly conserved nucleotides. Surprisingly, most of the RNA aptamers contained large deletions and rearrangements compared with the tRK1 molecule. We obtained a set of molecules containing the aminoacceptor (AA) stem of tRK1 determined by oligonucleotides used for RT-PCR, conserved regions corresponding to D-loops and T-loops, and variable sequences in the middle part of the molecule (Fig. 1A; Table 1).

Examples of selected RNAs from the SI-8 pool (selection for mitochondrial import only) shown in Table 1 represent the most frequently found sequences-SI-8-56 corresponds to $40 \%$ of all the aptamers, and SI-8-19 and SI-8-61 to $10 \%$ of each one. Statistical analysis of randomized nucleotides in the D-stem-loop region revealed the selected substitutions of several bases (Fig. 1A; Table 2): A15 (in tRK1) to G (as in tRK2); C17 (in tRK1) to GG/CG (U in tRK2); and C23 (in tRK1) to A (as in tRK2). The last substitution should severely disturb the D-stem stability. The sequence of the next 21 bases that should correspond to the anticodon arm-variable loop region of tRNA was the same in $65 \%$ of the aptamers of SI series, however, being quite deviant from the tRK1 sequence (Table 1).

We have not found any conservation in the anticodon region. This is in agreement with our results obtained by directed mutagenesis, suggesting that substitutions in the anticodon bases may modulate the import efficiency but do not abolish it (Kolesnikova et al. 2002). The sequence of the T-loop of tRK1 was conserved in all the aptamers, but the stretch of Gs that made the 5' -strand of the T-stem in tRK1 was deleted, thus making the formation of the normal T-stem impossible. Interestingly, another stretch of Gs has appeared in a different part of the sequence, namely, in the middle of the D-loop, due to a change of C17 to CG/CGG/GG (Tables 1,2).

The aptamers selected for import and pre-MSK-binding capacities (pool SIM-7) were all different, characterized by smaller lengths (57-65 nucleotides [nt]) and the presence of AC-rich stretches in the middle part of the molecule, replacing the anticodon-V-loop region of tRK1. Nucleotide substitutions in the D-loop region were partially different from those found in the SI pool: A15 has turned to C, and C17 to G/A (Tables 1, 2).

Several versions of the SI and SIM selection series were tested for mitochondrial import into isolated yeast mitochondria (Table 1). All of them were shown to have very high import efficiencies (three to five times higher than that of tRK1), thus validating our selection strategies and demonstrating the possibility of mitochondrial import for RNAs that have little in common with tRK1 structure.

\section{Structural features of selected RNAs}

Secondary structure predictions indicate that all the RNAs selected for mitochondrial targeting are quite deviant from the standard tRNA cloverleaf model.

TABLE 2. The frequency of bases in randomized positions of the D-arm region of RNA aptamers issued from the third (SI-3, SIM-3) and the final (SI-8, SIM-7) cycles of in vitro selection

\begin{tabular}{|c|c|c|c|c|c|c|c|}
\hline $\begin{array}{l}\text { Nucleotide } \\
\text { position }\end{array}$ & RNA pool & G & A & $\mathrm{T}$ & C & GG/CGG & CG \\
\hline \multirow[t]{4}{*}{15 (A in tRK1) } & SI-3 (21) & $33 \%(7)$ & $10 \%(2)$ & $14 \%(3)$ & $43 \%(9)$ & & \\
\hline & SI-8 (32) & $66 \%(21)$ & $6 \%(2)$ & $6 \%(2)$ & $22 \%(7)$ & & \\
\hline & SIM-3 (31) & $48 \%(15)$ & $6 \%(2)$ & $3 \%(1)$ & $43 \%(13)$ & & \\
\hline & SIM-7 (36) & $28 \%(10)$ & $8 \%(3)$ & $8 \%(3)$ & $56 \%(20)$ & & \\
\hline \multirow[t]{4}{*}{17 (C in tRK1) } & SI-3 (21) & $14 \%(3)$ & $19 \%(4)$ & $9.5 \%(2)$ & $24 \%(5)$ & $9.5 \%(2)$ & $24 \%(5)$ \\
\hline & SI-8 (32) & $12 \%(4)$ & $9 \%(3)$ & $6 \%(2)$ & $16 \%(5)$ & $19 \%(6)$ & $38 \%(12)$ \\
\hline & SIM-3 (31) & $35 \%(11)$ & $13 \%(4)$ & $17 \%$ & $35 \%(11)$ & & \\
\hline & SIM-7 (36) & $33 \%(12)$ & $31 \%(11)$ & $14 \%$ & $22 \%(8)$ & & \\
\hline \multirow[t]{4}{*}{$23(\mathrm{C}$ in $\mathrm{tRK} 1)$} & SI-3 (21) & $33 \%(7)$ & $19 \%(4)$ & $10 \%(2)$ & $38 \%(8)$ & & \\
\hline & SI-8 (32) & $6 \%(2)$ & $66 \%(21)$ & $19 \%(6)$ & $9 \%(3)$ & & \\
\hline & SIM-3 (31) & $26 \%(8)$ & $29 \%(9)$ & $13 \%(4)$ & $32 \%(10)$ & & \\
\hline & SIM-7 (36) & $17 \%(6)$ & $61 \%(22)$ & $11 \%(4)$ & $11 \%(4)$ & & \\
\hline
\end{tabular}

Numbers in parentheses correspond to the amount of plasmids sequenced. Base substitutions selected with reliability $>95 \%$ (calculated with STATISTICA) are indicated in bold. 
For the aptamers of the SI-8 library, in silico analysis revealed the same two types of secondary structures for all the selected RNAs. The first model is based on the assumption that the aminoacceptor stem of tRK1 is not disturbed. In this structure (referred to as the A-structure) (Fig. 2A), the long paired region could play the role of the D/anticodon helical domain of tRNA and in the three-dimensional model may be perpendicular to the acceptor stem. The last hairpin could play a stabilizing role. Thus, the molecule can be folded into a very close tRNA-like structure with all required distances and angles (Zagryadskaya et al. 2004).

The second model suggests the formation of an alternative helix (referred to as an F-stem) at the $3^{\prime}$-part of the molecule (F-structure) (Fig. 2A). The middle part of the structure (nucleotides 12-55) is just the same as in structure A, including the long ( $8 \mathrm{bp}$ ) paired region and the short "stabilizing" hairpin. Noteworthy, all the three stably selected substitutions in the D-arm of tRK1 (positions 15, 17, and 23) are involved in base-pairing, indicating their impact on the secondary structure.

For aptamers of the SIM-7 series, as for SI-8, two general types of structure can be predicted: structure A, containing the acceptor stem of $t R K 1$, and structure $F$, with the alternative helix at the $3^{\prime}$-part of the molecule (Fig. 2B).
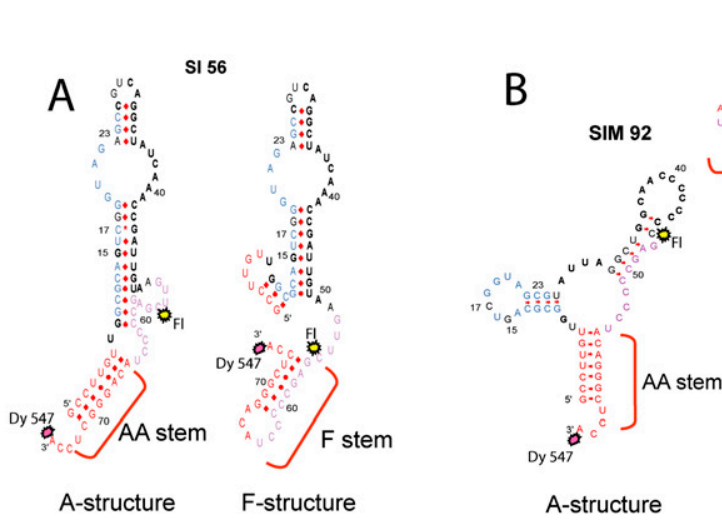

A-structure

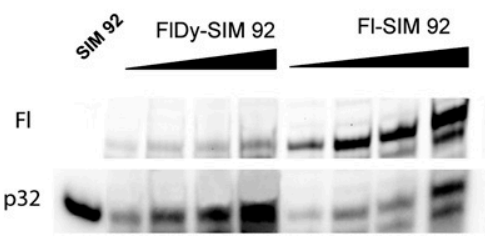

FIGURE 2. Secondary structure predictions and in-gel FRET analysis of selected RNA aptamers. $(A, B)$ Secondary structure prediction for RNA aptamers of $(A)$ SI and $(B)$ SIM series. Two types of structure are shown for each RNA, with a canonical aminoacceptor (AA) stem and with an alternative F-stem. (Red) Nucleotides corresponding to the tRK1 AA-stem;

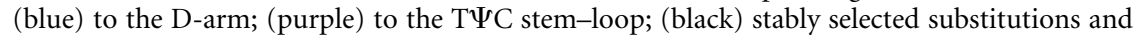
variable regions; fluorophore positions are shown by splashes; $(\mathrm{Fl})$ fluorescein. $(C)$ In gel FRET analysis of two selected RNA aptamers, (left panel) SI 56 and (right panel) SIM 92. Radioactive signals, p32, and fluorescence (ex. $488 \mathrm{~nm}$, em. $520 \mathrm{~nm}$ ), Fl, of increasing amounts of RNAs labeled by donor fluorophore only (Fl-RNA) or by both donor and acceptor fluorophores (FlDy-RNA), in a native $12 \%$ PAGE.
All the RNAs can be folded into two- or three-hairpin structures with a central loop containing a C-rich sequence that was selected for the aptamers of this series.

Comparing the RNA aptamers selected by either mitochondrial import or preMSK1p binding plus import, it can be noticed that one feature is in common for all RNAs: the possibility of F-hairpin formation. Moreover, for all the individual aptamers tested, the free energy of F-structure mation was lower than that of A-structure formation

\section{Study of the alternative structure formation by in-gel FRET}

To prove directly the possibility of F-structure formation for imported RNAs, we have used the in-gel FRET approach, allowing us to estimate distances between different points in the same RNA molecule labeled by fluorescent dyes, since the efficiency of energy transfer between a pair of fluorophores is inversely proportional to the sixth power of their distance in the range 20-80 $\AA$ (Walter 2003; Radman-Livaja et al. 2005). Two RNA aptamers issued from the SI and SIM selection procedure, SI 56 and SIM 92, have been chosen for the analysis. The donor fluorophore fluorescein $(\mathrm{Fl})$ was introduced into the positions corresponding to C56 of $\mathrm{tRK} 1$, conservative for all aptamers (Fig. 2; Table 1), and the acceptor fluorophore Dy547 was added at the 3 '-end of the RNA molecules. The distance between these positions should be quite different for two structural models proposed for selected RNAs (Fig. $2 \mathrm{~A}, \mathrm{~B})$ : in the structures type $\mathrm{A}$, we estimate a total distance between the dye attachment sites as $65 \pm 5 \AA$, while in alternative F-structures it should be shorter up to $25 \pm 5 \AA$, resulting in more efficient quenching of the donor fluorescence in the presence of the acceptor dye.

The efficiency of donor fluorescence quenching was measured in native PAGE for SI 56 and SIM 92 RNAs containing fluorescein only or both dyes, Fl and Dy547 (Fig. 2C). The simple Förster relation (Sun et al. 2006) yields a distance of $35.5 \pm 1 \AA$ for SI 56 RNA and $35 \pm$ $1 \AA$ for SIM 92 RNA (Table 3). Using the Förster relation for a fluctuating chain (Kobitski et al. 2008), we obtained even smaller values, $\sim 20 \AA$ for both RNAs, which are closer to the distance predicted for the F-structure.

These data indicate that RNA aptamers issued from the selection procedure and 
TABLE 3. FRET efficiencies and the calculated distances between the fluorophore dye attachment sites in the free RNAs and tRK1-protein complexes

\begin{tabular}{lrr}
\hline & $\begin{array}{c}\text { FRET efficiency, } E \\
(\%)\end{array}$ & $\begin{array}{c}\text { Distance } \\
(\AA)\end{array}$ \\
\hline Selected aptamer SI 56 & $94 \pm 0.7$ & $35.5 \pm 1$ \\
Selected aptamer SIM 92 & $94.5 \pm 0.6$ & $35 \pm 1$ \\
Free tRK1 & $93 \pm 0.8$ & $36 \pm 1$ \\
tRK1-MSK complex & $75 \pm 2$ & $46 \pm 1$ \\
tRK1-Eno2 complex & $98 \pm 0.5$ & $27 \pm 1$ \\
\hline
\end{tabular}

An average of two to three independent experiments is presented.

characterized by high mitochondrial import efficiency, in native conditions can be, at least partially, folded into the F-structure, as it was predicted in silico.

\section{Structural rearrangements of imported lysine tRNA}

Prediction of yeast tRNA ${ }^{\text {Lys }}$ secondary structures also shows a reasonable possibility to form the F-hairpin structure for tRK1, but not for the nonimported tRK2 molecule (Fig. 3A; Table 1). These findings allow us to hypothesize that formation of the alternative structure might serve as an import determinant, which is required for interaction of the imported tRNA with protein import factors.

However, our attempts to resolve the tRK1 structure in solution by chemical and enzymatic probing were not successful due to the presence of a mixture of different conformations (data not shown). To distinguish between classical and alternative conformations of tRK1, we used the in gel FRET approach for a T7-transcript of the $t R K 1$ gene labeled by the donor fluorophore fluorescein in position C56 of the T $\Psi C$ loop, and the acceptor fluorophore Dy547 added at the $3^{\prime}$-end of the tRNA molecule (Fig. 3A). In the classical tRNA L-shape structure, the distance between these positions was measured as 55-60 $\AA$ (Shi and Moore 2000), while the alternative structure formation should result in bringing the $3^{\prime}$-end and T $\Psi \mathrm{C}$ loop together up to $25 \AA$.

For the in vitro transcript of the $t R K 1$ gene containing the two fluorophores (referred to as FlDy-tRK1), the efficiency of donor fluorescence quenching yields a $36-\AA$ distance between dyes (Fig. 3B; Table 3), which corresponds to values obtained for selected RNA aptamers and is significantly less than the distance measured for the classical tRNA structure. Such a value may support the idea that the FIDy-tRK1 transcript, lacking post-transcriptional modifications, assumes a mixture of different conformations, as it was demonstrated for human mitochondrial tRNA ${ }^{\text {Lys }}$ (Kobitski et al. 2008), and can be partially folded into the F-structure.

We supposed that the interaction with proteins should fix one preferential conformation of the tRNA. Therefore, to monitor the changes in secondary structure of tRK1 during interaction with protein import factors (Eno2p and preMSK1p), we performed gel-shift assays and measured the FRET efficiency for FlDy-tRK1 in the tRNA-protein complexes separated in native PAGE (Fig. 3C,D). It appeared that formation of these RNA/protein complexes was not prevented by the presence of the fluorophores. In the complex with enolase 2, the distance between the fluorophores in FlDy-tRK1 was estimated as $27 \AA$, as it was predicted for the F-hairpin structure (Table 3). We can therefore suggest that enolase binds preferentially and/or stabilizes the particular conformation of tRK1, in which the $3^{\prime}$-end of tRNA and the TYC loop are close to each other.

After incubation of FlDy-tRK1 with preMSK1p, the distance between the $3^{\prime}$-end and the TYC loop of FlDytRK1 in the resulting complex was estimated as $46 \AA$ (Fig. 3C), demonstrating that tRK1 adopts another conformation, close to but slightly different from the classical L-form found in the complexes of tRNAs with their cognate aminoacyltRNA-synthetases (Cusack et al. 1996). This is consistent with our previous studies suggesting the RNA-chaperone abilities of yeast enolase (Entelis et al. 2006) and a particular way of interaction between tRK1 and preMSK1p that does not lead to tRNA aminoacylation (Tarassov et al. 1995).

To prove the impact of F-stem formation on the tRNA import ability and to study the role of other tRNA domains, we constructed and tested a set of artificial mini-RNAs.
A

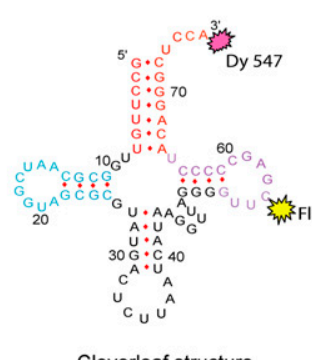

Cloverleaf structure

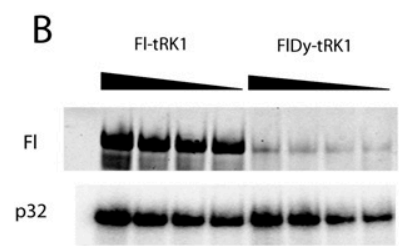

tRK1
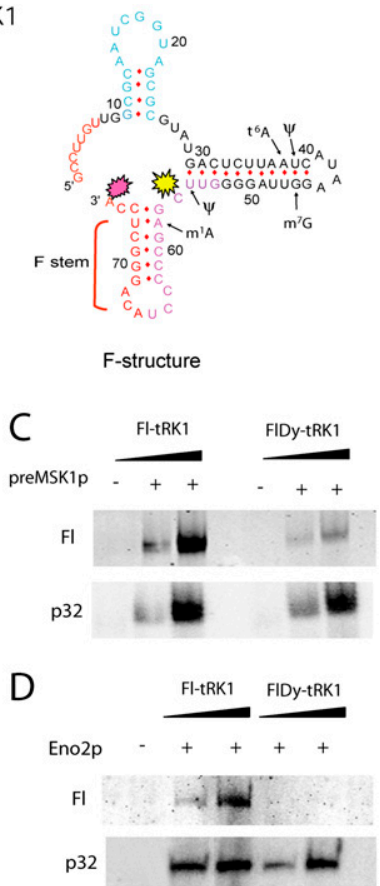

FIGURE 3. Study of conformational rearrangements in the tRK1 molecule by the FRET approach. (A) Secondary structures of tRK1 predicted by Mfold. tRK1 domains are colored as in Figure 2, and fluorophore positions are shown by splashes. Post-transcriptional modifications are indicated only in the tRK1 regions involved in the alternative structure. $(B-D)$ In-gel FRET analysis of $(B)$ tRK1, $(C)$ tRK1 complex with preMSK1p, and $(D)$ tRK1 complex with Eno2p. Radioactive signals (p32) and fluorescence (Fl) in native 9\% PAGE are presented, as in Figure 2D. 


\section{Mitochondrial import of small synthetic RNAs}

We have previously reported that the 25-nt fragment of the 3'-part of tRK1 (referred to as F1) (Fig. 4A) was able to be transported into yeast mitochondria on its own and could be folded into a stem-loop structure, corresponding exactly to the F-stem (Entelis et al. 1998).

The set of short molecules based on the F1 sequence was designed and tested for import into isolated yeast mitochondria (Fig. 4A). Two C-G base pairs in the F1 helix structure were substituted by G-C pairs in F1(GC) or by unpaired nucleotides C:A in F1(CA). The same values of import efficiency (Fig. 4B; Table 4) for F1 and F1(GC) indicate that stability of the stem, rather than its nucleotide sequence, has an impact on import ability of these small RNAs. The F1(CA) version where two base pairs are destroyed is still able to form a rather weak helix structure and is imported three times less efficiently than F1. This correlates with data obtained on Leishmania mitochondria suggesting the need of hairpin structure for the specific import of RNAs longer than $17 \mathrm{nt}$ (Rubio et al. 2000). Another small RNA named F1+H, containing an additional hairpin joint to $\mathrm{F}$, has the same

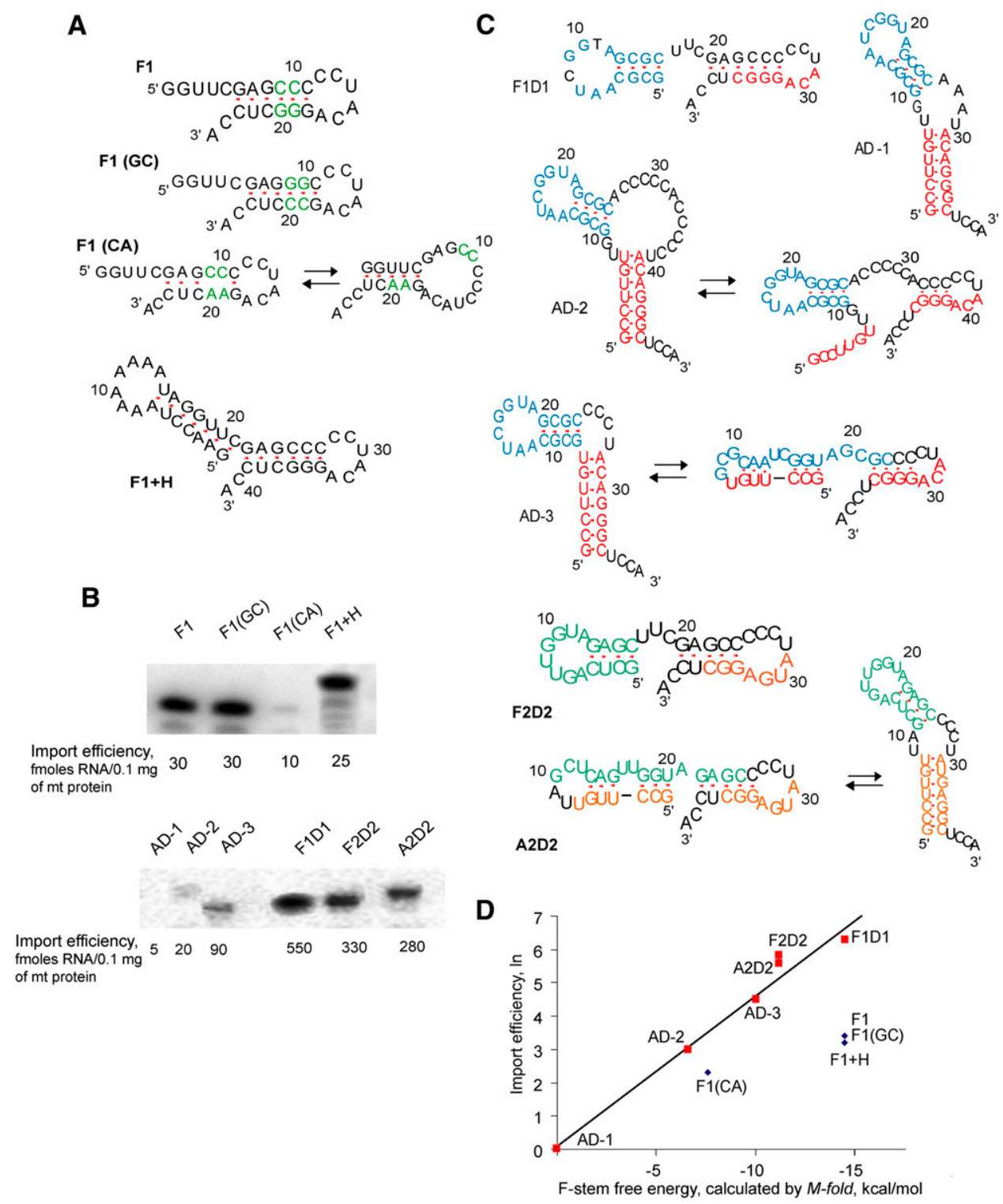

FIGURE 4. Structure and mitochondrial import of small synthetic RNAs. (A) Short RNA molecules based on the sequence of F1 (25-nt fragment of the tRK1 3'-part). Nucleotide substitutions are colored. (B) Examples of in vitro import test for the labeled short RNAs and its import efficiencies; see also Table 4. (C) Structure of synthetic RNA molecules composed of joined F-helix, D-arm, and/or aminoacceptor (AA-) stem of tRK1/tRK2. For several versions two alternative structures are shown. AA-stem regions are shown in red for tRK1 and in orange for tRK2; D-arms are in blue for tRK1 and in green for tRK2. (D) Dependence of synthetic RNA import efficiencies on the F-stem free energy (Mfold predicted). 
TABLE 4. Mitochondrial import properties of small synthetic RNAs

\begin{tabular}{lccc}
\hline & $\begin{array}{c}\text { Import } \\
\text { into yeast mitochondria } \\
\text { (fmol of RNA/0.1 mg } \\
\text { of mt protein) }\end{array}$ & $\begin{array}{c}\text { Import } \\
\text { into human mitochondria } \\
\text { (fmol RNA/0.1 mg } \\
\text { of mt protein) }\end{array}$ & $\begin{array}{c}\text { Mfold } \\
\text { predicted } \\
\text { free energy } \\
\text { of the F-stem } \\
\text { (kcal/mol) }\end{array}$ \\
\hline tRN1 & $50 \pm 5$ & $120 \pm 10$ & - \\
F1 & $30 \pm 5$ & ND & -14.5 \\
F1(GC) & $30 \pm 5$ & ND & -14.5 \\
F1(CA) & $10 \pm 5$ & ND & -7.6 \\
F1+H & $25 \pm 5$ & ND & -14.5 \\
F1D1 & $550 \pm 15$ & $750 \pm 15$ & -14.5 \\
AD-1 & $5 \pm 5$ & $5 \pm 5$ & 0 \\
AD-2 & $20 \pm 5$ & ND & -6.6 \\
AD-3 & $90 \pm 5$ & $50 \pm 5$ & -9.9 \\
A2D2 & $280 \pm 10$ & $300 \pm 10$ & -11.2 \\
F2D2 & $330 \pm 10$ & $350 \pm 10$ & -11.2 \\
\hline
\end{tabular}

ND, Not determined.

cies and their F-stems' stability for F1D1, $\mathrm{AD}-1, \mathrm{AD}-2$, and $\mathrm{AD}-3$, indicating the impact of F-stem formation on the importability of small synthetic RNAs.

This suggestion was supported by analysis of artificial RNAs A2D2 and F2D2, containing the D-arm of nonimported tRK2 and the AA-stem (or its $3^{\prime}$-part for F2D2) corresponding to mutant tRK2 version G1-C72; U73, which had been previously characterized by very efficient mitochondrial import (Entelis et al. 1998; Kazakova et al. 1999). Both short RNAs could be folded into 5-bp F-stem containing structures that correlated with a rather high level of mitochondrial import (Fig. 4B; Table 4). It was observed that F2D2 RNA was imported two times less efficiently than F1D1 RNA, the latter being character-

import efficiency as F1 (Fig. 4A,B). These results demonstrate the importance of the F-hairpin structure for small synthetic RNA import into isolated mitochondria. However, their import efficiencies less than $\mathrm{tRK} 1$ suggest implications of specific nucleotides, sequences, or structural motifs of other tRK1 domains in the import process.

To test the impact of different domains, another set of artificial RNA molecules composed of joint F-helix, D-arm, and/or aminoacceptor (AA-) stem of tRK1 or tRK2 was designed (Fig. 4C). Surprisingly, the RNA hairpin structure corresponding to the D-arm of tRK1 joined to the F-helix (named F1D1) led to a 10-fold increase of import abilities of the resulting RNA compared to F1 (Fig. 4B; Table 4). To verify the role of the D-arm in the import, we have constructed small RNAs containing the AA-stem and D-arm of tRK1 (referred to as AD-1, 2, and 3), differing by the length of the connector region between the two domains (Fig. 4C). Synthetic RNA AD-1 with a classical 2-nt connector region was not able to penetrate into yeast mitochondria, suggesting that the AA-stem joined to the D-arm of tRK1 cannot be imported on its own and does not contain a sufficient set of import determinants. On the contrary, versions $\mathrm{AD}-2$, differing from $\mathrm{AD}-1$ by the long C-rich loop region (as found in aptamers of SIM series), and AD-3 (without any connector) were imported into yeast mitochondria with increased efficiencies. Their import levels did not correlate with the stabilities of AA and D-stem-loop structures, but could be explained from the point of view of alternative structure formation. Indeed, the sequence of the AD-1 RNA completely excludes the possibility of $3^{\prime}$ hairpin structure formation. However, for the versions AD-2 and AD-3, it is possible to predict the F-stem structures with increasing stability ( 3 base pairs [bp] and 4 bp, correspondingly) (Fig. 4C). A diagram representation of these data (Fig. 4D) shows a clear correlation between the small RNAs' import efficien- ized by a more stable F-stem structure (Fig. 4C,D). Therefore, the results of the short RNA import analysis support the idea that the possibility of alternative F-hairpin formation at the $3^{\prime}$-end of tRNA is one of the mitochondrial import determinants.

Among all the short RNAs tested, those containing the $\mathrm{D}$-arm structure joined to the F-hairpin were characterized by very high import capacities (versions F1D1 and F2D2). However, version $\mathrm{F} 1+\mathrm{H}$, with a loop of seven adenosines joined to hairpin $\mathrm{F}$, had lower import ability than versions with a D-loop sequence (Fig. 4D). This might indicate that the D-loop sequence, conserved in most of the selected RNA aptamers, also serves as an "import-positive" feature, providing a platform for one of the protein import factors.

We have also tested the possibility for short artificial RNAs to be internalized by isolated human mitochondria in the presence of human proteins. We have shown that RNAs that were well imported into yeast mitochondria (F1D1, F2D2, and A2D2) were also imported into isolated HepG2 mitochondria with high efficiencies (Fig. 5A; Table 4).

F1D1 RNA characterized by the best import ability was then chosen to test the possibility of its mitochondrial import in vivo in cultured human cells. For this purpose, we have used the previously described approach of direct transfection of mammalian cells by purified tRNAs (Kohrer et al. 2001). We found that F1D1 RNA was stable in HepG2 cells at least $48 \mathrm{~h}$ after transfection, and was detected in the mitochondrial fraction after RNase and digitonin treatment, indicating its at least partial localization in the mitochondrial matrix (Fig. 5B). Efficiency of F1D1 RNA import into human mitochondria in vivo was five times higher than that of the tRK1 T7 transcript. These findings open the possibility of exploiting mitochondrial import of small artificial RNAs for biomedical applications. 
A

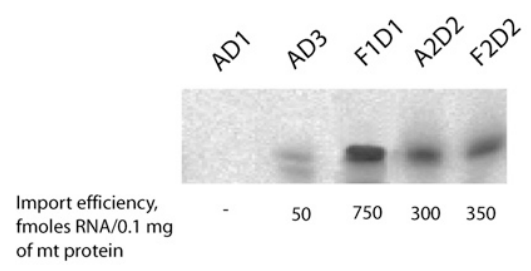

B

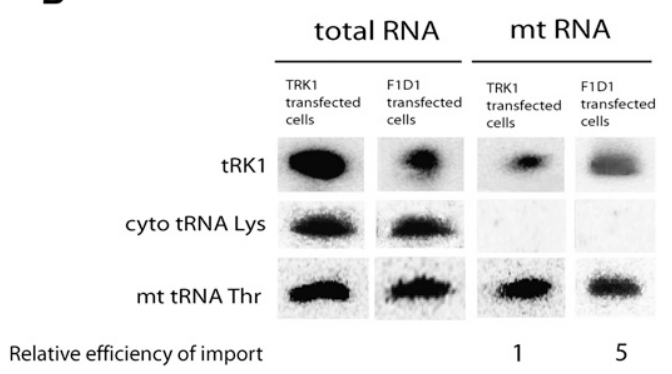

FIGURE 5. Import of small synthetic RNAs into human mitochondria. (A) Example of ${ }^{32} \mathrm{P}$-labeled RNAs import into isolated HepG2 mitochondria in the presence of human import-directing proteins. The mitochondrial import efficiencies were calculated as the average of three independent experiments; standard deviation values are indicated in Table 4. (B) Northern blot analysis of presence of tRK1 (T7 transcript) and synthetic RNA F1D1 in total and mitochondrial RNA preparations $48 \mathrm{~h}$ after transient transfection of HepG2 cells. Probes used for hybridization are indicated in the left column. Import efficiency of RNAs was estimated as a ratio between the signal obtained after hybridization with the anti-tRK1 probe and that obtained after hybridization with an oligonucleotide against the mitochondrial tRNA $^{\text {Thr }}$ in the mitochondrial RNA preparation. In order to compare import efficiencies of different RNAs, the values obtained were divided by the ratios calculated in the same way but in a total RNA preparation, which indicate the total level of each RNA in the transfected cells. The resulting normalized import efficiency of the tRK1 transcript was taken as 1 .

\section{DISCUSSION}

\section{In organello selection of importable RNA aptamers}

In the field of RNA import, one of the major challenges is to determine what controls the specificity of import. However, tRNA import signals are now known to be as diverse as the number of organisms studied (Salinas et al. 2008). In the protozoan Tetrahymena pyriformis, the UUG anticodon of the imported tRNA ${ }^{\text {Gln }}$ is essential and sufficient for mitochondrial targeting (Rusconi and Cech 1996). In Trypanosoma brucei, the T-stem nucleotides determine the localization of the tRNA ${ }^{\mathrm{Met}}$ (Bouzaidi-Tiali et al. 2007). Several studies suggested that tRNA import can be defined by the tertiary structure of the molecule. Thus, for mitochondria of Leishmania tarentolae, the nonspecific import of mini-helices smaller than 17 bases and a structural requirement for longer RNAs was demonstrated; however, the signals for importation of folded RNAs have not been determined (Rubio et al. 2000). In Leishmania tropica tRNAs, two import signals were identified: in the variable loop- $\mathrm{T}$ region and in the D-arm, the latter consisted of the secondary structure motif and A23 nucleotide identity (Bhattacharyya et al. 2002; Goswami et al. 2003). In higher plants, mutations abolishing tRNA mitochondrial import have been described in anticodon and D- and T-domains of different tRNAs (Duchene et al. 2009), raising the possibility that the $3 \mathrm{D}$ structure of tRNA, determined by interaction between $\mathrm{D}$ - and T-loops, is essential for import (Salinas et al. 2005).

The aim of this work was to identify the mitochondrial import determinants in the yeast tRNA ${ }^{\text {Lys }}$ molecule by the SELEX approach. This technique permits isolation of molecules with a high affinity to a target from a pool of heterologous RNAs by cycles of partitioning and amplification of selected sequences. SELEX has been successfully used to isolate RNA molecules that bind a particular protein from a pool of randomized sequences (Peterson et al. 1993, 1994). Applied to mitochondrial import of RNA, this method has been used to search for import signals in RNAs recognized by $L$. tropica mitochondrial receptors (Bhattacharyya et al. 2002). In this protozoan, the whole set of mitochondrial tRNAs is imported from the cytosol by a mechanism that is different from the one found in yeast (Mukherjee et al. 2007). A pool of random 16-mer sequences flanked by anchors has been subjected to selection for import into isolated L. tropica mitochondria, and thus permitted identifying a set of short "import signals" corresponding to the fragments of different tRNA domains (Bhattacharyya et al. 2002, 2003).

In the yeast $S$. cerevisiae, one of the two isoacceptor lysine tRNAs, tRK1, is imported into mitochondria. So we started our SELEX experiment from an initial library of tRK1-derived molecules containing 14 random nucleotides in positions that differ between imported tRK1 and nonimported tRK2 (Fig. 1A; Table 1). After seven to eight cycles of selection for import into isolated yeast mitochondria followed by RTPCR amplification, we obtained RNA pools demonstrating a 25-30-fold increase of import efficiency (Fig. 1E). This corresponds to the enhancement obtained for the RNA import into Leishmania mitochondria (Bhattacharyya et al. 2002) and indicates the successful enrichment of a randomized RNA pool with sequences capable of being imported into mitochondria.

However, analysis of individual selected RNAs revealed that we had not obtained the full-size tRNA molecules with changes in randomized positions, as it was expected, but a set of RNA-aptamers of different lengths, containing large deletions and rearrangements. This can be due to amplification artifacts as so-called "the tyranny of short motifs," since in SELEX experiments the shorter, less complex binding motifs may predominate (Conrad et al. 1995; Piasecki et al. 2009). In any case, all the individual RNA aptamers obtained and tested in this work demonstrated high levels of in vitro import (Table 1), indicating the successful selection of mitochondrial import determinants. This may reflect the flexibility of the mitochondrial import pathway and the possibility for different types of RNAs to bind the protein import 
factors and membrane receptors to be thereafter transported into the mitochondrial matrix, at least in vitro.

\section{Structural rearrangements of tRK1}

Analysis of the importable RNAs obtained in selection experiments allows us to suggest that at least one of the modes of interaction leading to RNA mitochondrial import could be realized through the alternative F-structure formation, different from a classical L-form tRNA model. This is the first evidence for implication of RNA secondary structure rearrangement in the mechanism of mitochondrial import selectivity, since all the previous studies suggested the role of the classical tRNA tertiary structure (Goswami et al. 2003; Salinas et al. 2005).

To prove the real existence of such conformational rearrangement, we used the FRET approach, a powerful technique allowing us to estimate distances between different points in the same RNA molecule labeled by fluorescent dyes (Walter 2003). The in-gel FRET method (RadmanLivaja et al. 2005) enabled us to measure the distance between the $3^{\prime}$-end and the T-loop of tRK1 in the complexes with its mitochondrial import factors, preMSK1p and Eno2p. We show that in the complex with targeting protein factor Eno2p, tRK1 adopts a particular conformation characterized by bringing closer nucleotides C56 and A75, as it was predicted for the F-hairpin structure (Fig. 3).

Our in silico structural predictions and the FRET approach have been performed with a synthetic transcript. Do in vivo post-transcriptional modifications of tRK1 allow the alternative structure formation? The tRK1 molecule contains modified nucleosides in 11 positions (compared to 16 in nonimported tRK2) (see Fig. 1A; Juhling et al. 2009), and only five of them are localized in the hairpin regions of the proposed alternative F-structure (Fig. 3A). A long hairpin, including the tRK1 V-loop and anticodon arm nucleotides, should not be destabilized by post-transcriptional modifications, since $\mathrm{t}^{6} \mathrm{~A}$ in position 37 , as well as $\mathrm{m}^{7} \mathrm{G} 46$, leave the hydrogen-bond capacity pattern unchanged, and pseudouridines $\Psi 39$ and $\Psi 55$ should have a stabilizing effect on basepairing (Helm 2006). The $\mathrm{m}^{1} \mathrm{~A} 58$ modification, which could disturb base-pairing A58-U73 in F-helix, was found only in a fraction of tRK1 molecules (Smith et al. 1971). Thus, no modifications able to prevent the alternative helices formation can be detected in the tRK1 structure. However, the post-transcriptional modifications in tRNAs have been considered to stabilize classical tRNA 3D folding, avoiding the alternative structures (for review, see Helm 2006). We can therefore suggest that nucleotide modifications in tRK1 restrict its possibility of folding into an F-structure, allowing mitochondrial import of $1 \%-5 \%$ of the tRK1 cytosolic pool, which is able to adopt this structure with the help of the RNA-chaperone protein factor enolase. This correlates with the observation that tRK1 in vitro transcript, being a poor substrate for aminoacylation, however, can be better imported into yeast mitochondria than modified tRK1 (Kolesnikova et al. 2002).

The idea of alternative tRNA folding first appeared in very early studies demonstrating tRNA misfolding into a conformation inactive for aminoacylation by a transition from a cloverleaf secondary structure to an extended one (Madore et al. 1999). Recently, by a single-molecule FRET technique, it was shown that a transcript of human mitochondrial tRNA ${ }^{\text {Lys }}$ in solution assumed a mixture of three conformations (unfolded, extended hairpin, and cloverleaf-based L-shape), depending on magnesium ion concentration and A9 base modification (Kobitski et al. 2008). Another type of alternative tRNA conformation, the " $\lambda$-form," was found in complex with one of the modification enzymes, ArcTGT. This enzyme modifies its buried target site (G15) by recognition of a tRNA marked by a profound conformational change making the $\mathrm{D}$-stem and the canonical core of the L-form structure completely disrupted (Ishitani et al. 2003).

All alternative tRNA conformations reported before suggested the intactness of the AA-stem. Here we hypothesize that to escape the cytosolic protein synthesis cycle and to enter inside the mitochondria, the tRNA molecule might adopt a completely different conformation, including the reorganization of the aminoacceptor, T-arm, and anticodon arm, retaining only the D-arm intact. This unusual folding can be induced or favored by interaction of aminoacylated tRK1 with RNA-chaperone enolase 2.

In our previous work (Entelis et al. 2006), yeast enolase was shown to have a capacity to reduce the $K_{\mathrm{d}}$ of the tRK1preMSK1p complex. In the presence of both proteins, no ternary complex was observed, and only tRK1-preMSK1p was detectable. Such a pattern is characteristic of consecutive reactions, indicating that Eno2p binds tRNA and then transfers it to the second protein, preMSK1p. Thus it was suggested that Eno2p could induce some conformational changes in tRNA. Data obtained in the present work confirm this hypothesis, since we demonstrate that in the complex with enolase, tRK1 adopts a particular conformation, in which the $3^{\prime}$-end of tRNA and the T $\Psi \mathrm{C}$ loop are close to each other.

We suggest that the housekeeping protein enolase is implicated not only in glycolysis and the targeting of imported tRNA toward the mitochondria, as it was shown previously, but also in the discrimination between cytosolic tRNAs partially imported into mitochondria, and nonimported ones. Enolase might induce the temporary conformational changes in the aminoacceptor stem of all the tRNA molecules; thereafter only those RNAs that are able to form a stable alternative F-stem proceed to the mitochondrial import pathway, including specific interactions with the carrier protein, preMSK1p, and membrane receptors. In the complex with preMSK1p, tRK1 adopts an unknown "intermediate" conformation, which should 
facilitate its re-folding into the classic cloverleaf-based L-shape structure needed for participation in mitochondrial translation.

\section{Impact of "import determinants" on the selectivity of mitochondrial targeting}

From the point of view of conformational rearrangement as an import selectivity determinant, some of our previous results should be re-discussed. Two yeast isoacceptor lysine tRNAs, imported tRK1 and nonimported tRK2, differ in several positions of the aminoacceptor stem (Fig. 1A; Table 1). Various versions of the $t R K 2$ gene with replacements in positions 1:72 and 73 have been expressed in yeast cells, and mutant tRNAs' mitochondrial import efficiencies were measured (Kazakova et al. 1999). It has been shown that introduction of a G1:C72 pair in the tRK2 context led to import of the mutant tRNA, whereas an additional mutation in the discriminator position 73 increased the import efficiency, which became almost the same as for tRK1 (Table 5). Therefore, bases G1:C72 and U73 at the end of the AA-stem were suggested to act as an import signature in the tRK2 context. So far, the role of these nucleotides, especially the one in the "discriminator" position 73 , has not been clear. To explain these data, here we compared the mutant versions' sequences from the point of view of the possibility to form an alternative helix structure at the $3^{\prime}$-end of the RNA molecules. One can see a clear correlation between mitochondrial import efficiency and the stability of the predicted F-stem at the $3^{\prime}$-end of these tRNAs (Table 5). In fact, the $3^{\prime}$-part of the nonimported tRK2 molecule cannot adopt any stable structure. Correspondingly, a 20-base fragment of its mutant version with an exchange of A72 for C72 (as in tRK1) can be folded into a rather stable alternative conformation and can be imported, whereas the exchange of two nucleotides, A72G73 for C72U73, stabilizes the F-hairpin, thus increasing the importability of tRNA. This can indicate the role of conformational changes, notably the F-helix formation, in tRNA mitochondrial import, not only in vitro, but also in living yeast cells.

TABLE 5. Possibility of the alternative F-stem formation for 20 -nt fragments at the 3 '-end of the mutant $t R K 1 /$ tRK2 versions

\begin{tabular}{|c|c|c|c|}
\hline RNA & $\begin{array}{l}\text { Sequence of } 20 \text { bases at } 3 \text { '-end of } \\
\text { tRNA molecule }\end{array}$ & $\begin{array}{l}\text { Mitochondrial import } \\
\text { efficiency, } \% \text { of tRK } 1^{\text {a }}\end{array}$ & $\begin{array}{l}\text { Mfold predicted dG } \\
\text { of F-stem formation, } \\
\mathrm{kcal} / \mathrm{mol}\end{array}$ \\
\hline tRK2 & $\begin{array}{c}\text { gagcCCCCuaugaggagcca } \\
\text { FF-FF FF-FF }\end{array}$ & $<1$ & 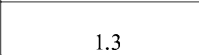 \\
\hline $\begin{array}{l}\text { tRK2 } \\
\mathrm{U} 1 \mathrm{G} ; \mathrm{A} 72 \mathrm{C}\end{array}$ & $\begin{array}{l}\text { gagcCCCCuaugaggCgcca } \\
\text { F-FFF-F } \quad \text { F-FFF-F }\end{array}$ & $55-60$ & -8.2 \\
\hline $\begin{array}{l}\text { tRK2 } \\
\text { U1G;A72C;G73U }\end{array}$ & $\begin{array}{ll}\text { gagcCCCCuaugaggCUCCa } \\
\text { FFFFF }\end{array}$ & $90-110$ & -10.3 \\
\hline tRK1 & \begin{tabular}{|lc} 
gagcccccuaCAGggCUcca \\
FFFFFF
\end{tabular} & 100 & -13.2 \\
\hline
\end{tabular}

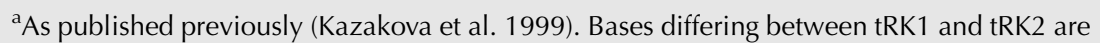
shown in bold; (F) nucleotides involved in the F-helix formation.
In yeast tRNAs ${ }^{\mathrm{Lys}}$, not only the aminoacceptor stem nucleotides, but also the wobble position C34 of the anticodon, have an impact on mitochondrial import (Kazakova et al. 1999; Kolesnikova et al. 2002). In the tRK1 alternative F-structure model, the anticodon nucleotides are involved in the long hairpin structure (Fig. 3A). Apparently, this hairpin can determine the overall structure stability. Therefore, C34-to-U34 substitution (as in tRK2) should lead to a destabilization of the long hairpin structure due to the three consecutive G:U pairs' formation. In native tRNAs, U34 is always modified, thus introducing steric conflicts and making the alternative F-structure formation less probable. We can therefore suggest that the anticodon domain of tRNA plays an auxiliary role in the mechanism of mitochondrial targeting selectivity, working mostly as a negative factor to prevent the conformational changes in nonimportable tRNAs and therefore guaranteeing the specificity of tRNAprotein interactions. Moreover, if the anticodon loop sequence could harm the conformational rearrangement needed for targeting, its deletion from the tRNA structure may even improve the mitochondrial import, as we can see for the RNA aptamers obtained in SELEX experiments (Table 1). Notably, the structure of small artificial RNA F1D1, demonstrating the best importability, is very close to the tRK1 alternative F-structure with the long hairpin region deleted (Figs. 3A, 4C). Therefore, the hypothesis of alternative tRNA conformation as one of the import determinants allows us to explain not only the results obtained in vitro with RNA aptamers, but also to understand the implication of previously identified "import determinants" in the mechanism of mitochondrial targeting selectivity.

\section{Mitochondrial import of RNAs as a therapeutic strategy}

The results presented here have another promising issue: some short synthetic RNAs were characterized by an extremely high efficiency of import into yeast as well as into human mitochondria. This supports our hypothesis that human cells possess a cryptic tRNA import mechanism that can be activated in the presence of importable RNAs and, in the case of specific need (either metabolic or genetic), provides the cell with an additional adaptive mechanism (Kolesnikova et al. 2004).

The use of the RNA mitochondrial import pathway can open a new door to treat severe pathological diseases associated with mtDNA mutations (Taylor and Turnbull 2005). One possible strategy consists of supplementation of defective mtDNA-encoded tRNAs with engineered tRNA alternatives expressed in the nucleus and imported into mitochondria. Two successful attempts to 
cure mitochondrial deficiency associated with the syndrome MERRF were already reported: we have used a cryptic tRNA import mechanism to target in the human mitochondria recombinant yeast tRNAs $^{\text {Lys }}$ (Kolesnikova et al. 2004). Mahata et al. (2006) have introduced the tRNA import apparatus from Leishmania into human cells to target a set of cytoplasmic tRNAs in the mitochondria. Other approaches based on the allotopic rescue of deleterious mtDNA mutations may be developed, as import of tRNAs with altered aminoacylation identities and suppressor tRNAs correcting mutations in protein-coding genes (Tarassov et al. 2007). Results obtained in the present study may be helpful for engineering of new importable tRNA molecules possessing the alternative folding abilities.

In the majority of patients, both mutant and wild-type mtDNA molecules are present in the same cell, a phenomenon known as "heteroplasmy." Antigenomic rescue of deleterious mtDNA mutations was proposed (but not yet realized), consisting in selective inhibition of the mutant mtDNA replication, thereby allowing propagation of only wild-type molecules (Taylor et al. 1997). The importable synthetic RNAs obtained in the present study cannot be expressed in vivo from the internal RNA polymerase III promoter. However, one of these RNAs introduced into human cells by a transient transfection procedure was shown to be stable in the cytoplasm and imported into the mitochondrial matrix with an efficiency five times higher than that of tRK1. Remembering that even low levels of transgenic tRNA expression permitted the correction of pathogenic effects due to mutation in human mitochondrial tRNA (Kolesnikova et al. 2004), this observation opens the possibility of creating a new mitochondrial vector system based on small RNA molecules, able to target therapeutic anti-replicative oligoribonucleotides into deficient human mitochondria.

\section{MATERIALS AND METHODS}

\section{Randomized RNA library design}

The initial pool of RNAs was generated by T7 transcription on a PCR amplificate of a 73-mer oligonucleotide O1 containing random nucleotides in 14 positions (Fig. 1A). PCR amplification was done using the oligonucleotides $\mathrm{O} 2$, containing the BstNI site to recreate the 3 '-terminal CCA sequence, and O3, containing the T7 RNA polymerase promoter for in vitro transcription (Table 6).

In vitro transcripts were gel-purified using a 12-cm-long, 10\% polyacrylamide gel containing $8 \mathrm{M}$ urea. In these conditions, tRNA molecules are not completely denaturated, and their mobility depends on the stability of the secondary structure. Two yeast lysine tRNAs, imported tRK1 and nonimported tRK2, being of the same length, were characterized by different mobility in this PAGE system (Entelis et al. 1998). Taking into account that RNA molecules of our randomized library could share the structural peculiarities of both tRK1 and tRK2 molecules, RNAs were eluted from a rather large spot of the gel, comprising the area of both lysine tRNAs.

Eluted RNAs were refolded by one cycle of heat denaturationrenaturation in presence of $0.5 \mathrm{mM} \mathrm{MgCl}_{2}$ and subjected either to binding to immobilized preMSK1p prior to import into isolated yeast mitochondria, or directly to import. After RNase treatment and swelling of mitochondria, RNA was isolated, RT-PCR amplified with $\mathrm{O} 2$ and $\mathrm{O} 3$ oligonucleotide primers, and used for the further rounds of selection or cloned into the pUC118 vector and sequenced. cDNA obtained after each round of selection was T7-transcribed and re-assayed for preMSK1p binding and in vitro import.

\section{In vitro import}

Yeast S. cerevisiae strain YPH500 was used for isolation of yeast mitochondria; human mitochondria and import directing proteins (IDPs) were isolated from the HepG2 cell line as described elsewhere (Entelis et al. 2002). Yeast IDPs were isolated from a pre-protein import-deficient strain, $\Delta \mathrm{TOM} 20_{\mathrm{IRV}}$, carrying plasmid pG11T6 with the MSK1 gene to overexpress the precursor form of MSK1p (Kazakova et al. 1999).

The assay of ${ }^{32} \mathrm{P}$-labeled RNA import into isolated yeast or human mitochondria was performed in the presence of yeast or human IDP as described (Entelis et al. 2002). A 15-min incubation of 
mitochondria with a labeled RNA has been followed by a mitochondria re-purification step, RNase treatment to eliminate all the external RNA, disruption of the outer mitochondrial membrane by osmotic shock (swelling), re-purification of mitoplasts, and RNA isolation. Imported RNAs were analyzed by PAGE in a $12 \%$ polyacrylamide gel containing $8 \mathrm{M}$ urea, and quantification of results was done by Typhoon-Trio scanner using ImageQuantTools software (GE Healthcare). To estimate the import efficiency, 50 fmol of corresponding ${ }^{32} \mathrm{P}$-labeled RNA were loaded on the same gel. All the manipulations with mitochondria, up to the RNA isolation step, normally take at least $1 \mathrm{~h}$, so the amount of imported RNA detected by gel scanning should correspond to the labeled RNA that has penetrated into the mitochondrial matrix and did not degrade there in $1 \mathrm{~h}$.

For in organello selection experiments, the same protocol has been used; the only difference was that isolated yeast mitochondria were incubated with an unlabeled mixture of RNA molecules (100 pmol per $50 \mu \mathrm{g}$ of mitochondrial protein) in a final volume of $100 \mu \mathrm{L}$. For the sixth, seventh, and eighth rounds of selection, the volume of reaction was increased to $500 \mu \mathrm{L}$, to decrease the concentration of RNA-binding ligands and mitochondrial receptors and, therefore, to increase the selection stringency.

\section{RNA synthesis and manipulation}

Small artificial RNAs were obtained by PCR amplification of corresponding sequences (the oligonucleotides are listed in Table 6) followed by cloning, sequencing, and transcription. RNA transcripts obtained in vitro using T7 RNA polymerase (Promega) were gel-purified and refolded by one cycle of heat denaturationrenaturation in the presence of $0.5 \mathrm{mM} \mathrm{MgCl}$. Aminoacylation was done with the recombinant yeast cytoplasmic lysyl-tRNA synthetase (KRS1p) as described (Entelis et al. 1998). For RTPCR, AMV reverse transcriptase (Promega) was used. For each RT-PCR, a control reaction without reverse transcriptase was performed.

\section{preMSK1p binding}

PreMSK1p-binding efficiency was quantified by immunoprecipitation of $5^{\prime}-{ }^{32} \mathrm{P}$-labeled individual tRNA/preMSK1p complexes with anti-MSK antibodies as described (Entelis et al. 1998). For selection experiments, 100 pmol of RNA were incubated with Sepharose CL4B-BrCN-immobilized recombinant preMSK1p (10 pmol per assay) in $20 \mathrm{mM}$ HEPES-KOH (pH 6.8), $20 \mathrm{mM} \mathrm{KCl,} 2.5 \mathrm{mM}$ $\mathrm{MgCl}_{2}, 1 \mathrm{mM} \mathrm{ATP}$, and $5 \mathrm{mM}$ dithiothreitol. After the fifth round of selection, the amount of immobilized pre-MSK was decreased to $0.1 \mathrm{pmol}$. After $30 \mathrm{~min}$ of incubation at $20^{\circ} \mathrm{C}$, Sepharose beads were washed twice with the same buffer, and RNA was eluted with $7 \mathrm{M}$ urea, phenol-extracted, and precipitated by ethanol.

\section{RNA import in vivo}

For transfection of HepG2 cells, $6 \mu \mathrm{g}$ of RNA per $60 \mathrm{~cm}^{2}$ of confluent cells were used. Transfection was carried out by using the Lipofectamine 2000 reagent (Invitrogin) according to the manufacturer's protocol. Two days after transfection, mitochondria were isolated and purified as described (Entelis et al. 2001), and total and mitochondrial tRNAs were resolved in denaturing gels and analyzed by Northern hybridization with $5^{\prime}-{ }^{32} \mathrm{P}$-labeled oligonucleotide probes against the $3^{\prime}$-part of yeast tRNA ${ }_{\mathrm{CUU}}^{\mathrm{Lys}}$ (for tRK1 and small synthetic RNAs detection), human cytosolic tRNA $^{\text {Lys }}$ (to check possible cytosolic contamination in mtRNA preparation), and human mitochondrial tRNA ${ }^{\text {Thr }}$ (Table 6). The import efficiency of RNAs was then estimated after quantification in a Typhoon-Trio scanner as a ratio between the signal obtained after hybridization with an anti-tRK1 probe and that obtained after hybridization with an oligonucleotide against the mitochondrial tRNA ${ }^{\text {Thr }}$ in the mitochondrial RNA preparation, as described previously (Smirnov et al. 2008). In order to compare import efficiencies of different RNAs, the total level of each RNA in transfected cells should be taken into account and normalized. For this, the import efficiencies were divided by the ratios calculated in the same way but in a total RNA preparation, which indicates the total level of RNA. The resulting normalized import efficiency of tRK1 transcript was taken as 1.

\section{In silico RNA analysis}

To predict 2D RNA structures and estimate the free energy $(d G)$, the Mfold program was mainly used, but the alternative programs contrafold, pfold, and the ViennaRNA package were also used with similar results. The Malign package was used to align primary structures of RNAs, and the Statistica package to evaluate SELEX results.

\section{In gel FRET analysis}

Fluorescent RNAs were constructed by the splint-ligation method (Kurschat et al. 2005). T7 transcripts corresponding to 1-51 nt of tRK1 and a selected aptamer SI 56, or to 1-45 nt of a selected aptamer SIM 92 (Table 1), were ligated to the chemically synthesized RNA fragments corresponding to the $3^{\prime}$-part of the tRK1 molecule (52-76 nt). Fluorescent groups were introduced into the RNA fragments (Thermo Scientific, Dharmacon): fluorescein (donor) in the C56 position, for Fl-RNAs; fluorescein in C56 and Dy 547 (acceptor) added to the 3 '-end (A76), for double-labeled FlDyRNAs (Table 6). After ligation, full-size RNAs were gel-purified, $5^{\prime}-{ }^{32} \mathrm{P}$-labeled, and re-purified on a $12 \%$ urea-PAGE. Gel-shift assays with recombinant proteins were performed as described previously (Entelis et al. 2006). To obtain a stable tRK1-enolase complex, the recombinant yeast Eno2p with an $\mathrm{H} 373 \mathrm{~F}$ mutation (Entelis et al. 2006) was used. Dy547-labeled tRK1 was not able to form a complex with KRS1p.

Fluorescein (exitation $488 \mathrm{~nm}$, emission $520 \mathrm{~nm}$ ) signals were measured in gel with the use of a Typhoon-Trio scanner; radioactive signals were measured in the same gels using a BAS-MS Imaging Plate (Fujifilm) at the same scanner and quantified with ImageQuantTools software. The efficiency of energy transfer $(E)$ was calculated as the extent of donor fluorescence quenching in doublelabeled (by donor and acceptor) tRK1, with the use of the standard equation:

$$
\frac{I_{\mathrm{da}}[\mathrm{d}]}{[\mathrm{da}]}=I_{\mathrm{d}}(1-E)
$$

where $I_{\mathrm{da}}$ and $I_{\mathrm{d}}$ are fluorescein fluorescence intensities of RNA containing the both donor and acceptor, and with donor alone, respectively; [da] and [d] are radioactive signals of RNA with both 
donor and acceptor, and with donor alone, respectively. The distance between fluorophores $(R)$ was calculated from the equation:

$$
R=R_{0}\left(\frac{1}{E}-1\right)^{1 / 6}
$$

where $R_{0}$ is the Förster critical distance, for the pair fluorescein/ Dy547, $R_{0}=56 \AA$ (Sun et al. 2006). Estimation of distances between the dye attachment sites for the different RNA conformers was done as described (Kobitski et al. 2008), and calculations based on the Förster relation for a fluctuating chain are as in Kobitski et al. (2007).

\section{ACKNOWLEDGMENTS}

We thank Alexandre Smirnov for help in RNA 2D structure prediction and critical reading of the manuscript and Aline Keilbach for administrative help. This work was supported by the Centre National de Recherche Scientifique (CNRS), Universite de Strasbourg (UdS), Association Française contre les Myopathies (AFM), Agence Nationale de la Recherche (ANR), Fondation pour la Recherche Médicale (FRM), Russian Foundation for Basic Research (RFBR), and ARCUS cooperation program Alsace-Russia-Ukraine.

Received September 5, 2009; accepted February 1, 2010.

\section{REFERENCES}

Bhattacharyya SN, Chatterjee S, Adhya S. 2002. Mitochondrial RNA import in Leishmania tropica: Aptamers homologous to multiple tRNA domains that interact cooperatively or antagonistically at the inner membrane. Mol Cell Biol 22: 4372-4382.

Bhattacharyya SN, Chatterjee S, Goswami S, Tripathi G, Dey SN, Adhya S. 2003. 'Ping-pong' interactions between mitochondrial tRNA import receptors within a multiprotein complex. Mol Cell Biol 23: 5217-5224.

Bouzaidi-Tiali N, Aeby E, Charriere F, Pusnik M, Schneider A. 2007. Elongation factor la mediates the specificity of mitochondrial tRNA import in T. brucei. EMBO J 26: 4302-4312.

Brandina I, Graham J, Lemaitre-Guillier C, Entelis N, Krasheninnikov I, Sweetlove L, Tarassov I, Martin RP. 2006. Enolase takes part in a macromolecular complex associated to mitochondria in yeast. Biochim Biophys Acta 1757: 1217-1228.

Conrad RC, Baskerville S, Ellington AD. 1995. In vitro selection methodologies to probe RNA function and structure. Mol Divers 1: 69-78.

Cusack S, Yaremchuk A, Tukalo M. 1996. The crystal structures of T. thermophilus lysyl-tRNA synthetase complexed with E. coli tRNA $^{\text {Lys }}$ and a T. thermophilus tRNA ${ }^{\text {Lys }}$ transcript: Anticodon recognition and conformational changes upon binding of a lysyladenylate analogue. EMBO J 15: 6321-6334.

Duchene AM, Pujol C, Marechal-Drouard L. 2009. Import of tRNAs and aminoacyl-tRNA synthetases into mitochondria. Curr Genet 55: $1-18$.

Entelis NS, Krasheninnikov IA, Martin RP, Tarassov IA. 1996. Mitochondrial import of a yeast cytoplasmic tRNA ${ }^{\text {Lys }}$ : Possible roles of aminoacylation and modified nucleosides in subcellular partitioning. FEBS Lett 384: 38-42.

Entelis NS, Kieffer S, Kolesnikova OA, Martin RP, Tarassov IA. 1998. Structural requirements of tRNA ${ }^{\text {Lys }}$ for its import into yeast mitochondria. Proc Natl Acad Sci 95: 2838-2843.

Entelis NS, Kolesnikova OA, Dogan S, Martin RP, Tarassov IA. 2001. $5 \mathrm{~S}$ rRNA and tRNA import into human mitochondria. Comparison of in vitro requirements. J Biol Chem 276: 45642-45653.
Entelis N, Kolesnikova O, Kazakova H, Brandina I, Kamenski P, Martin RP, Tarassov I. 2002. Import of nuclear encoded RNAs into yeast and human mitochondria: Experimental approaches and possible biomedical applications. Genet Eng (N Y) 24: 191-213.

Entelis N, Brandina I, Kamenski P, Krasheninnikov IA, Martin RP, Tarassov I. 2006. A glycolytic enzyme, enolase, is recruited as a cofactor of tRNA targeting toward mitochondria in Saccharomyces cerevisiae. Genes \& Dev 20: 1609-1620.

Frechin M, Senger B, Braye M, Kern D, Martin RP, Becker HD. 2009. Yeast mitochondrial Gln-tRNA ${ }^{\mathrm{Gln}}$ is generated by a GatFABmediated transamidation pathway involving Arclp-controlled subcellular sorting of cytosolic GluRS. Genes \& Dev 23: 1119-1130.

Goswami S, Chatterjee S, Bhattacharyya SN, Basu S, Adhya S. 2003. Allosteric regulation of tRNA import: Interactions between tRNA domains at the inner membrane of Leishmania mitochondria. Nucleic Acids Res 31: 5552-5559.

Helm M. 2006. Post-transcriptional nucleotide modification and alternative folding of RNA. Nucleic Acids Res 34: 721-733.

Ishitani R, Nureki O, Nameki N, Okada N, Nishimura S, Yokoyama S. 2003. Alternative tertiary structure of tRNA for recognition by a post-transcriptional modification enzyme. Cell 113: 383-394.

Juhling F, Morl M, Hartmann RK, Sprinzl M, Stadler PF, Putz J. 2009. tRNAdb 2009: Compilation of tRNA sequences and tRNA genes. Nucleic Acids Res 37: D159-D162.

Kamenski P, Kolesnikova O, Jubenot V, Entelis N, Krasheninnikov IA, Martin RP, Tarassov I. 2007. Evidence for an adaptation mechanism of mitochondrial translation via tRNA import from the cytosol. Mol Cell 26: 625-637.

Kazakova HA, Entelis NS, Martin RP, Tarassov IA. 1999. The aminoacceptor stem of the yeast tRNA ${ }^{\text {Lys }}$ contains determinants of mitochondrial import selectivity. FEBS Lett 442: 193-197.

Kobitski AY, Nierth A, Helm M, Jaschke A, Nienhaus GU. 2007. $\mathrm{Mg}^{2+}$-dependent folding of a Diels-Alderase ribozyme probed by single-molecule FRET analysis. Nucleic Acids Res 35: 2047-2059.

Kobitski AY, Hengesbach M, Helm M, Nienhaus GU. 2008. Sculpting an RNA conformational energy landscape by a methyl group modification-a single-molecule FRET study. Angew Chem Int Ed Engl 47: 4326-4330.

Kohrer C, Xie L, Kellerer S, Varshney U, RajBhandary UL. 2001. Import of amber and ochre suppressor tRNAs into mammalian cells: A general approach to site-specific insertion of amino acid analogues into proteins. Proc Natl Acad Sci 98: 14310-14315.

Kolesnikova OA, Entelis NS, Mireau H, Fox TD, Martin RP, Tarassov IA. 2000. Suppression of mutations in mitochondrial DNA by tRNAs imported from the cytoplasm. Science 289: 19311933.

Kolesnikova O, Entelis N, Kazakova H, Brandina I, Martin RP, Tarassov I. 2002. Targeting of tRNA into yeast and human mitochondria: The role of anticodon nucleotides. Mitochondrion 2: 95-107.

Kolesnikova OA, Entelis NS, Jacquin-Becker C, Goltzene F, ChrzanowskaLightowlers ZM, Lightowlers RN, Martin RP, Tarassov I. 2004. Nuclear DNA-encoded tRNAs targeted into mitochondria can rescue a mitochondrial DNA mutation associated with the MERRF syndrome in cultured human cells. Hum Mol Genet 13: 2519-2534.

Kurschat WC, Muller J, Wombacher R, Helm M. 2005. Optimizing splinted ligation of highly structured small RNAs. RNA 11: 19091914.

Madore E, Florentz C, Giege R, Lapointe J. 1999. Magnesiumdependent alternative foldings of active and inactive Escherichia coli RRNA $^{\text {Glu }}$ revealed by chemical probing. Nucleic Acids Res 27: 3583-3588.

Mahata B, Mukherjee S, Mishra S, Bandyopadhyay A, Adhya S. 2006. Functional delivery of a cytosolic tRNA into mutant mitochondria of human cells. Science 314: 471-474.

Martin RP, Schneller JM, Stahl AJ, Dirheimer G. 1977. Study of yeast mitochondrial tRNAs by two-dimensional polyacrylamide gel electrophoresis: Characterization of isoaccepting species and search for imported cytoplasmic tRNAs. Nucleic Acids Res 4: 3497-3510. 
Mukherjee S, Basu S, Home P, Dhar G, Adhya S. 2007. Necessary and sufficient factors for the import of transfer RNA into the kinetoplast mitochondrion. EMBO Rep 8: 589-595.

Peterson ET, Blank J, Sprinzl M, Uhlenbeck OC. 1993. Selection for active E. coli tRNA ${ }^{\text {Phe }}$ variants from a randomized library using two proteins. EMBO J 12: 2959-2967.

Peterson ET, Pan T, Coleman J, Uhlenbeck OC. 1994. In vitro selection of small RNAs that bind to Escherichia coli phenylalanyl-tRNA synthetase. J Mol Biol 242: 186-192.

Piasecki SK, Hall B, Ellington AD. 2009. Nucleic acid pool preparation and characterization. Methods Mol Biol 535: 3-18.

Radman-Livaja M, Biswas T, Mierke D, Landy A. 2005. Architecture of recombination intermediates visualized by in-gel FRET of $\lambda$ integrase-Holliday junction-arm DNA complexes. Proc Natl Acad Sci 102: 3913-3920.

Rinehart J, Krett B, Rubio MA, Alfonzo JD, Soll D. 2005. Saccharomyces cerevisiae imports the cytosolic pathway for Gln-tRNA synthesis into the mitochondrion. Genes \& Dev 19: 583-592.

Rubio MA, Liu X, Yuzawa H, Alfonzo JD, Simpson L. 2000. Selective importation of RNA into isolated mitochondria from Leishmania tarentolae. RNA 6: 988-1003.

Rubio MA, Rinehart JJ, Krett B, Duvezin-Caubet S, Reichert AS, Soll D, Alfonzo JD. 2008. Mammalian mitochondria have the innate ability to import tRNAs by a mechanism distinct from protein import. Proc Natl Acad Sci 105: 9186-9191.

Rusconi CP, Cech TR. 1996. Mitochondrial import of only one of three nuclear-encoded glutamine tRNAs in Tetrahymena thermophila. EMBO J 15: 3286-3295.

Salinas T, Schaeffer C, Marechal-Drouard L, Duchene AM. 2005. Sequence dependence of tRNA ${ }^{\text {Gly }}$ import into tobacco mitochondria. Biochimie 87: 863-872.

Salinas T, Duchene AM, Marechal-Drouard L. 2008. Recent advances in tRNA mitochondrial import. Trends Biochem Sci 33: $320-329$.
Shi H, Moore PB. 2000. The crystal structure of yeast phenylalanine tRNA at $1.93 \AA$ resolution: A classic structure revisited. RNA 6: 1091-1105.

Smirnov A, Tarassov I, Mager-Heckel AM, Letzelter M, Martin RP, Krasheninnikov IA, Entelis N. 2008. Two distinct structural elements of 5S rRNA are needed for its import into human mitochondria. RNA 14: 749-759.

Smith CJ, Ley AN, D’Obrenan P, Mitra SK. 1971. The structure and coding specificity of a lysine transfer ribonucleic acid from the haploid yeast Saccharomyces cerevisiae $\alpha$ S288C. J Biol Chem 246: 7817-7819.

Sun X, Mierke DF, Biswas T, Lee SY, Landy A, Radman-Livaja M. 2006. Architecture of the 99 bp DNA-six-protein regulatory complex of the $\lambda$ att site. Mol Cell 24: 569-580.

Tarassov I, Entelis N, Martin R. 1995. Mitochondrial import of a cytoplasmic lysine-tRNA in yeast is mediated by cooperation of cytoplasmic and mitochondrial lysyl-tRNA synthetases. EMBO J 14: 3461-3471.

Tarassov I, Kamenski P, Kolesnikova O, Karicheva O, Martin RP, Krasheninnikov IA, Entelis N. 2007. Import of nuclear DNAencoded RNAs into mitochondria and mitochondrial translation. Cell Cycle 6: 2473-2477.

Taylor RW, Turnbull DM. 2005. Mitochondrial DNA mutations in human disease. Nat Rev Genet 6: 389-402.

Taylor RW, Chinnery PF, Turnbull DM, Lightowlers RN. 1997. Selective inhibition of mutant human mitochondrial DNA replication in vitro by peptide nucleic acids. Nat Genet 15: 212-215.

Tuerk C, Gold L. 1990. Systematic evolution of ligands by exponential enrichment: RNA ligands to bacteriophage T4 DNA polymerase. Science 249: 505-510.

Walter NG. 2003. Probing RNA structural dynamics and function by fluorescence resonance energy transfer (FRET). In Current protocols in nucleic acid chemistry (ed. SL Beaucage et al.), Chap. 11, Unit 11.10. Wiley, New York.

Zagryadskaya EI, Kotlova N, Steinberg SV. 2004. Key elements in maintenance of the tRNA L-shape. J Mol Biol 340: 435-444. 

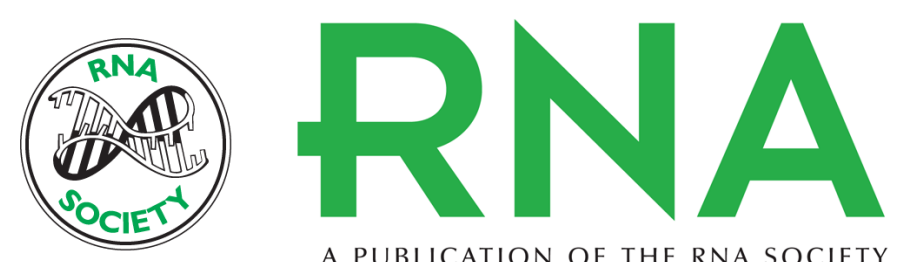

A PUBLICATION OF THE RNA SOCIETY

\section{Selection of RNA aptamers imported into yeast and human mitochondria}

Olga Kolesnikova, Helena Kazakova, Caroline Comte, et al.

RNA 2010 16: 926-941 originally published online March 26, 2010

Access the most recent version at doi:10.1261/rna.1914110

\section{References This article cites 50 articles, 18 of which can be accessed free at: http://rnajournal.cshlp.org/content/16/5/926.full.html\#ref-list-1}

\section{License}
Email Alerting Receive free email alerts when new articles cite this article - sign up in the box at the Service top right corner of the article or click here.

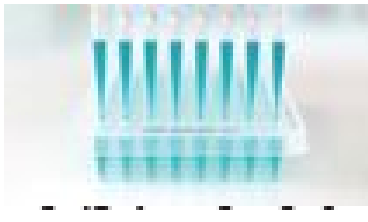

\section{Providing Precise Solutions for} your research.

To subscribe to RNA go to:

http://rnajournal.cshlp.org/subscriptions 